\title{
ARTículo
}

\section{Los usos de la etnohistoria: cañaris e incas en la construcción nacional ecuatoriana y peruana}

\section{The uses of ethnohistory: Cañaris and Incas in the Ecuadorian and Peruvian national construction}

\author{
Mirko Solari \\ https://orcid.orq/0000-0003-0356-9094 \\ msolarip@unmsm.edu.pe \\ Universidad Nacional Mayor de San Marcos
}

\begin{abstract}
RESUMEN
Tras las independencias, los Estados nacionales andinos se erigen sobre la base de la cartografía colonial. En la antigua Audiencia de Quito (actual Ecuador), la obra de Juan de Velasco constituye un significativo anclaje identitario, vinculado a una sucesión de hechos mitológicos y disputas dinásticas al interior de la confederación Quito-Puruhá. En el Perú, se advierte una apropiación del legado inca por parte de las élites criollas y, en ambos casos, la historiografía que enaltece el pasado prehispánico convive con la marginalidad de las poblaciones indígenas. La incorporación de los cañaris al relato nacional ecuatoriano revela múltiples desafíos. Este pueblo, masivamente afectado por los traslados mitmas durante el incanato, no formaba originalmente parte de la confederación Quito-Puruhá (base prehispánica de la ecuatorianeidad); más bien, se opuso a ella. Asimismo, la tendencia de identificar a Atahualpa como inca «proto-ecuatoriano» contrasta con el apoyo de los cañaris a Huáscar, «inca peruano». Si a ello se suma el apoyo de algunos sectores de cañaris (locales y mitmas) a la empresa colonial hispana, la imagen de este pueblo resultaría desfavorable para ambas historiografías nacionales. La apropiación selectiva del pasado, las oposiciones republicanas ancladas en presuntas desavenencias prehispánicas, así como una lectura etnocéntrica de la historia («legitimidad real», dinastías, discutibles cartografías, imaginarios civilizatorios), caracterizan los usos de la etnohistoria en la elaboración de proyectos republicanos en Ecuador y Perú.
\end{abstract}

Palabras clave: Cañaris; incas; Estado-nación; historiografía; etnohistoria.

\section{ABSTRACT}

After Independence, the Andean nation states were built on the basis of colonial cartography. In the old Audience of Quito (now Ecuador), Juan de Velasco's work constitutes a significant base for identity, linked to a succession of mythological events and dynastic disputes within the Quito-Puruhá confederation. In Peru there is an appropriation of the Inca legacy by the "Creole" elites and, in both cases, the historiography that exalts the pre-Hispanic history coexists with the marginality of the indigenous people. The incorporation of the Cañaris into the Ecuadorian national historiography reveals multiple challenges. This people, massively affected by the mitma transfers during the Inca period, was not part of the Quito-Puruhá confederation (pre-Hispanic base of Ecuadorian identity); rather, they opposed it. Also, the tendency to identify Atahualpa as a "proto-Ecuadorian" Inca contrasts with the support of the Cañaris to Huáscar, conceived as a "Peruvian Inca". This particularity, and the support of some sectors of Cañaris (local and mitmas) to the Hispanic colonial endeavor, can be perceived as unfavorable for both national historiographies. The selective appropriation of the past, republican oppositions based on presumed pre-Hispanic disagreements, as well as an ethnocentric reading of history ("real legitimacy", dynasties, controversial cartography, imaginary of civilization), characterize the uses of ethnohistory in the elaboration of republican projects in Ecuador and Peru.

Keywords: Cañaris; Incas, nation-state; historiography; ethnohistory.

(C) Los autores. Este artículo es publicado por ISHRA, Revista del Instituto Seminario de Historia Rural Andina de la Facultad de Ciencias Sociales de la Universidad Nacional Mayor de San Marcos. Este es un artículo de acceso abierto, distribuido bajo los términos de la licencia Creative Commons Atribución 4.0 Internacional (CC BY 4.0) [https://creativecommons.org/licenses/by/4.0/deed.es] que permite el uso, distribución y reproducción en cualquier medio, siempre que la obra original sea debidamente citada de su fuente original. 


\section{Introducción}

El presente texto forma parte de una investigación más amplia en torno a la etnicidad cañari en la región andina (Solari Pita, 2015). La visión diacrónica y, en este caso concreto, el apelar a la etnohistoria, permiten abordar múltiples dimensiones del estudio de las identidades colectivas en los Andes. En principio, constatamos que la región ha conocido diversas etapas de articulación de las construcciones étnicas, las cuales se vinculan a contextos políticos y sociales mayores, como los de los periodos prehispánico, colonial y republicano. Partiendo de la existencia de una identidad quechua contemporánea (particularmente visible en Ecuador, Perú y Bolivia), ciertas manifestaciones regionales en su interior evidencian una compleja configuración étnica previa que termina asumiendo, fundamentalmente debido a factores lingüísticos, el rostro de una etnicidad quechua panandina. En efecto, la quechuización lingüística del incanato, pero sobre todo de la Colonia, es un eje articulador de identidades prehispánicas diferenciadas.

Sobre la base de una etnogénesis quechua en la región andina, el presente texto busca analizar de qué manera los Estados nacionales, surgidos hace dos siglos, encuentran anclajes identitarios en un pasado prehispánico abierto a una permanente reinterpretación historiográfica por parte de sus élites políticas e intelectuales. El empleo -selectivo- del legado inca permite construir la peruanidad, pero, a la vez, constituye un desafío que condicionará la escritura de las historiografías ecuatoriana y boliviana. Estas reconocerán la impronta del Tahuantinsuyo en ambos países, pero, en paralelo, deberán apelar a otros referentes capaces de legitimar narrativas históricas propias. Así, respectivamente, scyris y tiahuanacos son dos entidades étnicas prehispánicas que brindarán singularidad nacional, particularmente entre fines del siglo XIX y la primera mitad del siglo XX. En el ámbito regional del sur ecuatoriano, la reivindicación de la herencia cañari permitirá alimentar escenarios duales, aparentemente contradictorios, que suponen una paralela valoración del incario.

Este texto busca mostrar el dinamismo de las construcciones étnicas en los Andes, así como el uso de las mismas para legitimar la existencia e intereses de Estados nacionales como el ecuatoriano o el peruano. Efectivamente, el análisis de la identidad cañari, así como la asimilación del referente inca en la región, permiten constatar que las fuentes historiográficas de legitimidad de los países andinos tienden a ser construidas por actores intelectuales y políticos exteriores al mundo indígena. Paradójicamente, los actores sociales regionales y nacionales que construyen referentes identitarios nativos suelen asociarse a sectores que, en la práctica, son hostiles a las reivindicaciones indígenas. Las movilizaciones étnicas de las últimas décadas muestran, sin embargo, un cambio en esta tendencia. Para dar cuenta de estos procesos, nos insertaremos inicialmente en las versiones etnohistóricas acerca de la diáspora de los mitmas cañaris en los Andes, y repasaremos luego los escenarios de construcción de la ecuatorianeidad y peruanidad. Finalmente, en Batallas por la civilización, evaluaremos la vigencia de narrativas colectivas que buscan legitimar el presente, a partir de la valoración reivindicativa, o la eventual invención de la historia regional y nacional (Anderson, 1991; Hobsbawm y Ranger, 1983)

\section{Los cañaris: una antigua diáspora andina}

El pueblo cañari, originario del actual austro ecuatoriano, es registrado desde el inicio de la conquista hispana; sus antecedentes se adentran en el pasado mítico regional, así como en estudios arqueológicos que tienden a identificarlo como una confederación de las cuencas fluviales de la zona, surgida ante presiones sociales y políticas externas ( $c f r$. Arriaga, 1965; Cieza de León, 1968; Iglesia, 1977). Los cañaris fueron, sin duda, actores protagónicos durante la expansión inca a lo largo de los Andes. Por motivos que están aún en debate y análisis, se trata de uno de 
los pueblos que se vieron más afectados por la política de traslados mitma, encontrándose entre los estudios etnohistóricos decenas de colonias de cañaris entre el norte de Quito y el actual sur boliviano (Crespo, 2003; Espinoza, 1967, 1999; Garzón, 2004; Miño, 1982; Oberem y Hartmann, 1979; Santos, 1986)

Esta particularidad de los cañaris, es decir, su presencia a lo largo de todo el Tahuantinsuyo durante la Conquista, parece reafirmar la idea del apoyo de algunos sectores de esta etnia a la empresa colonial hispana. De la mano de este presunto colaboracionismo, diversas fuentes ponen énfasis en proporcionar referencias negativas acerca de este pueblo ( $c f r$. Murúa, 1987). Ciertamente, algunas aproximaciones etnohistóricas nos permiten confirmar que, en virtud de prerrogativas coloniales, los descendientes de mitmas cañaris de localidades como Chiara (Ayacucho, Perú) o Copacabana (La Paz, Bolivia), estuvieron exentos del pago de tributos y de la obligatoriedad de la mita minera, por lo menos, hasta bien avanzado el siglo XVII (Espinoza, 1999; Santos, 1986). Un estudio comparativo de diversas comunidades de destino de mitmas cañaris muestra que no es posible generalizar la idea de un status étnico de privilegio de esta etnia a lo largo de todo los Andes, pues los vínculos con el poder colonial varían profundamente según la región, el papel que aparentemente cumplieran durante la Conquista o las primeras décadas de la Colonia, así como en virtud de la capacidad de agencia de sus líderes étnicos (a menudo asociados a mitmas chachas) para defender las mencionadas prerrogativas coloniales (Solari Pita, 2015).

\section{Quitus, puruhás, scyris y cañaris: la construcción de la nación ecuatoriana desde el pasado precolombino}

La historiografía ecuatoriana encuentra en los relatos de Juan de Velasco (1960) una importante fuente de afirmación de la singularidad nacional. El antiguo Reyno de Quito constituiría su anclaje en el pasado prehispánico y la base de la nación. En efecto, en su obra del siglo XVIII, Juan de Velasco ilustra tempranamente el surgimiento de un sentimiento nacional, de una patria que se iba diseñando décadas antes del inicio del proceso independentista. Así, el relato de Juan de Velasco da lugar a una idea de continuidad entre los denominados reinos precolombinos, la colonial Audiencia de Quito y el Ecuador contemporáneo. Cabe señalar que esta noción es producto del trabajo intelectual de historiadores de los siglos XIX y XX, pues Velasco no llega a conocer el periodo republicano. Sin embargo, el relato histórico que el sacerdote había esbozado en el siglo XVIII, sugería ya la mencionada continuidad histórica. Al inicio de esta periodificación, el reino de Quito es presentado como una sucesión de reinados, linajes y alianzas de poder, profundamente impregnada de un espíritu dinástico de trasfondo occidental, una tradición de legitimación del pasado prehispánico, ya presente en Garcilaso de la Vega en el siglo XVI ( $c f r$. Bernand, 2006; Garcilaso de la Vega, 1965).

La denominada dinastía de los scyris habría gobernado el territorio Quitu-Cara durante unos cinco siglos a través del mando de una quincena de reyes. Un problema de ausencia de sucesión masculina sería sabiamente resuelto mediante la incorporación de una heredera, Toa, suponiendo un cambio normativo que, a su vez, habría permitido nuevas alianzas con los pueblos del sur, como los puruhás. Precisamente, ello da lugar a la idea de la confederación Quito-Puruhá a la que hemos venido haciendo alusión. En efecto, el matrimonio entre Toa y Duchicela constituyó una hábil salida al supuesto problema dinástico, lo cual habría fomentado más aún el crecimiento de la confederación. En ese marco, Duchicela XII habría fomentado la expansión territorial, conquistado el Cañar, una región cuya nacionalidad, la de los cañaris, es concebida por Velasco como tan importante como la de Quito (Velasco, 1960). 
A inicios del siglo XIX, una vez abierta la opción política de crear un nuevo Estado nacional sobre la base de la Audiencia de Quito, la historia del reino homónimo se corresponde perfectamente con la necesidad de establecer los remotos orígenes del embrionario país. En efecto, la narración de Velasco integra, con relativa armonía, los diferentes territorios del Ecuador republicano, aunque subrayando la necesaria primacía de Quito, que se convierte en la capital. La ya mencionada integración del Cañar a la confederación Quito-Puruhá constituye una clave historiográfica significativa, pues confirma la adscripción de los cañaris a la matriz prehispánica de la ecuatorianeidad y, adicionalmente, precede al paso de los incas por la región del austro ecuatoriano ( $c f r$. Garzón, 2004). Ya en el siglo XX, la tradición historiográfica inaugurada por Juan de Velasco será profundamente cuestionada por historiadores como González Suárez (1903) y Jijón y Caamaño (1919). El también historiador Carlos Manuel Larrea (1988) describe de la siguiente manera la radical crítica de Jijón y Caamaño a los postulados de Velasco:

Hábilmente trata de aniquilar la historia acumulando extensa lista de autores que, según Jijón, nada dicen de Schyris, Caras ni Duchicelas ... Concluye Jijón, en forma sarcástica, mostrando la patraña inspirada por dar a la patria bien amada, de la que se encontraba desterrado, una aureola grandiosa en su pasada historia que el nostálgico jesuita quería que no fuese menos que la del Imperio de los Incas ... Jijón ataca duramente al Padre Velasco ... y termina: «es la historia de los Schyris fábula perniciosa que urge borrar de todo libro serio». (Larrea, 1988, pp. 60-61)

En los intentos de articular las referencias historiográficas con las narrativas locales (y regionales) surgen ciertos desafíos. En principio, originalmente los cañaris no formaban parte de la confederación Quito-Puruhá (base de la ecuatorianeidad); por el contrario, se oponían a ella. Por otro lado, la tendencia a identificar a Atahualpa como un inca «proto-ecuatoriano» contrasta con el apoyo de los cañaris a Huáscar, un «inca peruano». Paralelamente, diversas fuentes parecen mostrar el apoyo de ciertos sectores de cañaris (locales y mitmas) a la empresa colonial hispana (Espinoza, 1999; Santos, 1986), y ello supone un reto no solo para la historiografía ecuatoriana, sino también para la peruana, en la que resaltan diversos casos análogos. Ya sea como colaboradores locales de los españoles o como herederos de los incas al norte del Tahuantinsuyo, los cañaris, su historia y su coherente pasado deben resolver el problema de la necesidad de escribir linealmente -y de forma aparentemente armoniosa- la historia nacional y la de sus antepasados. Se trata, en efecto, de una condición para la invención de la tradición a la que están sujetas aquellas comunidades imaginadas que son los Estados nacionales contemporáneos (cfr. Anderson, 1991; Hobsbawm y Ranger, 1983).

\section{El incacentrismo peruano como base de la nacionalidad}

En el Perú, los amargos resultados de la Guerra del Pacífico (1879-1883) son, por lo general, atribuidos a la inexistencia de una clase política capaz de integrar a la población de origen indígena al imaginario nacional. En este contexto, la mayor parte de los esfuerzos políticos e intelectuales orientados a reforzar la idea de nación proponen una imagen ciertamente idealizada de los incas, aunque queda pendiente la tarea de articular los íconos del pasado a la degradada realidad de los indígenas del presente. La apropiación del legado inca constituye así un proyecto que asocia fines políticos a un espíritu de orgullo en torno a la historia patria. Sin embargo, esta construcción historiográfica es profundamente paradójica, particularmente al interior de la élite criolla, que tendía a perpetuar arcaicos sistemas de explotación de la tierra y de la mano de obra nativa. Presente también en los contenidos de la educación formal, esta ambigüedad puede ser resumida en la frase "incas sí, indios no" (Méndez, 1995). 
En la medida en que la apropiación oficial de la herencia inca por parte de las élites criollas encuentra aceptación social, existe una cierta coherencia discursiva que consolidará la imagen de un pasado ideal, la cual es particularmente visible en el Perú rural quechua. Incluso si en algunas regiones peruanas los incas son percibidos como conquistadores de las etnias locales, estos encarnan la noción de héroes civilizadores, el emblema del «antiguo Perú» (cfr. Flores Galindo, 1994). Cabe señalar que esta percepción de los actores sociales fundamentalmente andinos no es precisamente producto de la labor de élites urbanas ilustradas, sino de narrativas históricas del mundo rural. Si bien la caída del imperio inca está parcialmente vinculada a las disputas de poder entre Huáscar y Atahualpa, el denominado conflicto fratricida no se asocia, como en Ecuador, a las bases de un diferendo entre naciones. En otras palabras, mientras en el Ecuador Atahualpa es asociado a una proto-ecuatorianeidad, en el Perú, Huáscar y Atahualpa son considerados como dos «antiguos peruanos», dos incas dignos de la admiración en torno a la proto-peruanidad de ambos (Solari Pita, 2015). No obstante, existen también caracterizaciones que buscan la descalificación de Atahualpa, lo cual se da en clara alusión a la «mayor peruanidad» con la que se identificaría a Huáscar. Como lo señala Franklin Pease:

Huáscar ha sido sindicado tradicionalmente como el representante típico y "legítimo" de la élite cuzqueña y todavía es un lugar común señalarlo como una víctima de su infortunio y de la felonía de su "hermano sanguíneo" que era apoyado por un sector disidente de la élite. Se dio la imagen de un Huáscar bueno y tradicional, religioso y vinculado a la casta sacerdotal, paralela a la cual se había creado la visión de un Atahualpa sanguinario y regicida, ambicioso y aficionado a crueldades sin sentido. (Pease, 1963, p.182).

Sin negar la posible competencia entre Cusco y Quito durante los últimos años del incario, es importante constatar cómo se va configurando un discurso de carácter moralizador, particularmente al interior de la historiografía peruana. Raúl Porras Barrenechea atribuye el inicio de la debacle inca a la conquista de Quito, tras lo cual la civilización del sur empieza a perder sus valores intrínsecos. Cabe resaltar el lugar que ocupan ciertas nociones de género (en este caso, ligadas a la masculinidad y al libertinaje sexual), como factores que pueden marcar la solidez o debilidad de un imperio.

La conquista de Quito es la pérdida del Tahuantinsuyo ... Los orejones, la invencible y austera casta de los anteriores reinados, educada en la abstinencia, la privación y el trabajo, había perdido su vigor. Ya no comían maíz crudo ni viandas sin sal, no se abstenían de mujer durante los ejercicios preparatorios de su carrera militar, ni realizaban trabajos de mano, ni eran los primeros en el salto y la carrera. De las clásicas ceremonias instituidas por Túpac Yupanqui para discernir el título de orejón, sólo conservaban el amor a la chicha. Mientras más beber, más señor es, llegó a decirse ... El vínculo federativo que era el sostén del Imperio, no era ya así libre y voluntario o conseguido por la persuasión, sino impuesto por la fuerza. (Porras Barrenechea, 1990, p. 134)

Hemos mencionado una suerte de leyenda negra colonial que concibe a la nación cañaris como «traidora, turbulenta y mentirosa» (como se citó en Miño, 1982, p. 186), para retomar los términos de Fray Martín de Murúa. Estas características bien podrían asociarse a los reclamos del cronista Guamán Poma de Ayala, quien denuncia la situación privilegiada de los primeros descendientes de mitmas cañaris de Chiara, en Ayacucho, en contraste con la mayor parte de la población nativa de la época (Guamán Poma, 1980). En efecto, este conjunto de representaciones negativas, a propósito de los cañaris, está presente en la historiografía peruana, pero no llega a 
asumir un peso significativo. En nuestro abordaje etnológico, este tipo de relatos no son ubicables en regiones en las que ha habido presencia de mitmas cañaris. Al menos entre actores sociales de regiones receptoras de colectividades de esta etnia (Cajamarca, Lambayeque, Ayacucho, entre otras), no tiende a encontrarse una imagen negativa del pasado mitma septentrional (Solari Pita, 2015).

\section{Batallas por la civilización: cuando el pasado legitima el presente}

En concordancia con lo anteriormente señalado, en las representaciones nacionales del pasado prehispánico peruano, las etnias precolombinas ( $\mathrm{y}$ su condición o status) se encuentran subordinadas a la hegemónica relevancia del Tahuantinsuyo. Sin embargo, existen tradiciones regionales como las de los chancas, en Ayacucho, los wancas, en la región Junín, o los moche, en la costa norte, a menudo puestas en valor por élites locales peruanas desde hace un siglo, aproximadamente. En una dinámica en la que la mayor antigüedad afirma una mayor legitimidad histórica, diversas tradiciones culturales regionales o locales empiezan a ser reivindicadas como anteriores a los incas, lo cual, en el Ecuador o Bolivia, supone una suerte de freno al incacentrismo andino, ciertamente instrumentalizado por la historiografía peruana (Garzón, 2004).

En el Perú, se asiste actualmente a la emergencia de procesos de etnicización y reescritura del pasado que marcan agendas colectivas de diversa naturaleza (Robin-Azevedo y Salazar-Soler, 2009). En el caso específico del Ecuador, el siguiente texto da cuenta del posicionamiento de los cañaris en términos de héroes civilizatorios, sin los cuales ni el incanato ni la Conquista hubiesen podido consolidarse en el austro ecuatoriano. Nos encontramos, en definitiva, ante una lucha por el pasado que apela a nociones de civilización, ciencias y artes para estructurar imaginarios de desarrollo cultural. Estos aluden -pero también antagonizan- a los imaginarios de prestigio histórico del Ecuador y del Perú:

Los Cañaris civilizadores de los Andes es una categorización que nace de una nueva interpretación de los hechos en el que se destaca un protagonismo suprarregional en toda el área andina (Ecuador, Perú y Bolivia), concretado primero en el apoyo a la estructuración del sistema imperial de los Incas, y luego en el afianzamiento del sistema colonial español por casi dos siglos ... El llamado «incacentrismo» [es un concepto] que lleva a creer que la única cultura que alcanzó un alto grado de desarrollo en todos los ámbitos fue la inca. ... A lo anotado debemos sumar el aporte cultural y laboral que ofrecieron los Cañaris a la estructuración del sistema estatal inca o la condición física y habilidad fue un aporte importante para la construcción de varias obras y para los propósitos militares o se suma también el aporte intelectual, el conocimiento de artes, ciencia, medicina, artesanía, etc ... Hatun Cañar y Guapondélig se convirtieron en importantes capitales culturales de los incas, articuladas política y económicamente al gran proyecto andino del Tahuantinsuyo y cuya preponderancia alcanzó el nivel de otro Cusco. (Garzón, 2004 , pp. 13, 30, 59)

Con el fin de legitimar la construcción nacional, desde hace dos siglos los Estados nacionales latinoamericanos han emprendido la tarea de crear historiografías en las que el pasado prehispánico asume cierta armonía interna en relación con el presente republicano ( $f f r$. Kristal, 1991). Sin embargo, los cañaris (o las historias que sobre ellos se han escrito) son objeto de miradas ambiguas, particularmente al interior de la tradicional visión historiográfica ecuatoriana. Así, los cañaris evocan una versión local de la magnificencia inca, mientras que, por otro lado, esta historiografía nacional tiene la labor de explicar el apoyo de los cañaris a la conquista hispana. 
No obstante, al estar asociados al Perú, los incas no constituyen un punto de referencia ideal, como sí ocurre del otro lado de la frontera, donde la historiografía peruana sitúa en ellos el anclaje de la nacionalidad. Según esta lógica de apropiación de las imágenes del pasado con el fin de reforzar visiones del presente, el inca Atahualpa, supuestamente nacido en Quito y asociado a la ciudad de Tomebamba, en el Cañar, se convierte en una suerte de símbolo de la ecuatorianeidad. En un solo personaje se concentra el elemento civilizador inca y un claro poder regional al interior de un territorio actualmente ecuatoriano. Por su lado, la historiografía peruana reconoce la existencia de la disputa entre Huáscar y Atahualpa, pero se esmera en no vincularla a dos Estados nacionales modernos, privilegiando así una imagen unitaria de los incas, antepasados de los peruanos del presente. Efectivamente, una visión fragmentaria del Tahuantinsuyo no contribuiría a reforzar la imagen de un pasado ideal. Sin embargo, como hemos visto, existe ciertamente una tendencia entre los historiadores peruanos a legitimar la imagen de Huáscar, y ello no es una mera casualidad. Confirmando el carácter artificial de las narraciones republicanas ecuatoriana y peruana (o de buena parte de ellas), Franklin Pease esclarece la naturaleza de esta disputa dinástica entre los hermanos:

Siempre se ha presentado a los últimos incas como hermanos encarnizadamente enemigos, dirigentes activos de dos facciones rivales que los endiosaban. También se ha hecho hincapié en la legitimidad de Huáscar y en la bastardía de Atahualpa. Se ha discutido hasta la saciedad si el último inca era hijo de una concubina cuzqueña -una india quilaco, dice Cieza-, de la irreal princesa Paccha de Quito, como lo quiso el padre Juan de Velasco, o de un indígena de Chachapoyas al decir de Huamán Poma. Hay que decir una vez más que no puede encararse el conflicto entre el Cuzco y Quito como la lucha fratricida sobre la que tanto se ha escrito. Huáscar y Atahualpa representan facciones diversas, pero el problema está en identificarlas. ... La legitimidad de que nos hablan los cronistas está calcada de moldes europeos y está directamente vinculada ala institución matrimonial cristiana, monogámica e indisoluble y muy distinta de la institución similar entre los incas ... La cuestión del nacimiento cuzqueño o quiteño de Atahualpa ... no tiene la importancia que se le ha querido adjudicar. Tampoco tiene interés fundamental que su madre haya sido Paccha (princesa procedente de un país fantástico cuya invención es propiedad del padre Velasco, cronista del Quito colonial y que ha sido desmentido tantas veces). (Pease, 1963, pp. 180-181)

\section{Corolario}

Una larga cadena de hechos históricos e intereses colectivos contribuye a configurar diversas visiones, a veces antagónicas, en torno al pasado prehispánico de los cañaris desde ambos lados de la frontera. La apropiación nacional de una imagen positiva del pasado, paralela a su propia elaboración, tiende a legitimar los imaginarios nacionales a la vez que regionales, una labor que, en este caso, se consolida con el indigenismo. A fines del siglo XX, la efervescencia de las identidades se va fortaleciendo en buena parte del mundo indígena andino, asumiendo distintos rostros en cada país y región. Los cañaris no son ajenos a esta tendencia, pero las imágenes que se han forjado acerca de ellos ya han sido objeto de visiones y tratamientos ambiguos por parte de las historiografías ecuatoriana y peruana. Los usos de la etnohistoria cañari confirman cómo se construyen los Estados nacionales sobre la base de representaciones arbitrarias del pasado prehispánico. Los retos sociales contemporáneos de las colectividades andino-amazónicas muestran, entre otras cosas, una cierta tendencia a escribir y reinterpretar las historias locales y regionales desde parámetros menos ligados al poder de las élites tradicionales o de la pertenencia 
a los Estados nacionales. Es preciso recordar que los proyectos de nación, las historiografías, así como diversas narrativas regionales acerca del pasado prehispánico, proceden de élites que ejercen una suerte de ventriloquía en relación con las voces de los actores sociales indígenas (Guerrero, 1994). Recordemos, asimismo, que en buena parte del mundo rural andino, quizá las utopías tiendan a situarse en el pasado antes que en el futuro. (Flores Galindo, 1994)

\section{Referencias bibliográficas}

ANDERSON, Benedict. (1991). Comunidades Imaginadas. Reflexiones sobre el origen y difusión del nacionalismo. México D.F: Fondo de Cultura Económica.

Arriaga, Jesús. (1965) [1922]. Apuntes de arqueología cañari. Cuenca: Universidad de Cuenca.

Bernand Muñoz, Carmen. (2006). Un Inca platonicien. Garcilaso de la Vega, 1539-1616. Paris: Fayard.

CieZA DE León, Pedro. (1968) [1551]. El señorio de los Incas Yupanguis y de sus grandes hechos y gobernación. Segunda parte de la Crónica del Perú, escrita por Cieza y publicada por Marco Jiménez de la Espada en Madrid, 1880: El Perú a través de los siglos. Primera serie, tomo 2. Lima: Editores Técnicos Asociados.

Crespo Toral, Hernán. (2003). «Desde la penumbra. Un retrato del exilio o la presencia de los cañaris en el Cusco». Homenaje a José Alcina Franch. Revista Española de Antropología Americana [volumen extraordinario], 277290.

Espinoza Soriano, Waldemar. (1967). El primer informe etnológico sobre Cajamarca: Año de 1540. Revista Peruana de Cultura, (11-12), 5-41.

Espinoza SoRiano, Waldemar. (1999). Los Chachapoyas y Cañares de Chiara (Huamanga), Aliados de España. En Waldemar Espinoza, Etnohistoria Ecuatoriana. Estudios y Documentos (pp. 299-320). Quito: Abya - Yala.

Flores Galindo, Alberto (1994). Buscando un Inca: identidad y utopia en los Andes. Lima: Editorial Horizonte.

Garcilaso de la Vega, Inca. (1965) [1609]. Comentarios Reales de los Incas. Madrid: Biblioteca de Autores Españoles.

Garzón EsPinoza, Mario (2004). Los cañaris civilizadores de los Andes. Estudio etnohistórico de los cañaris en el Perú. Cañar: Consejo Provincial del Cañar.

González SuÁRez, Federico (1922). Estudio histórico sobre los Cañaris: pobladores de la antigua provincia del Azuay. Cuenca: Universidad del Azuay.

González SuÁrez, Federico. (1903) [1893]. Historia General de la República del Ecuador. Quito: Tiempos Antiguos.

Guamán Poma de Ayala, Felipe. (1980) [ca. 1615-1617?]. Nueva Crónica y Buen Gobierno. México D.F.: Siglo XXI.

Guerrero, Andrés (1994). Una imagen ventrílocua: el discurso liberal de la desgraciada raza indígena a fines del siglo XIX. En Blanca Muratorio (Ed.), Imágenes e imagineros. Representaciones de los indígenas ecuatorianos, Siglos XIX y XX (pp.197-252).Quito: Facultad Latinoamericana de Ciencias Sociales,

Hobsbawm, Eric y Ranger, T. (1983). Invention of Tradition. Cambridge: Cambridge University Press.

IgLEsIA, Ángel María (1977). Cañar: Síntesis Históricas. Azogues: Editorial América.

JIJÓN Y CAAMAÑo, Jacinto. (1919). Examen crítico de la veracidad de la Historia del Reino de Quito del Padre Juan de Velasco, de la Compañía de Jesús. Boletín de la Sociedad Ecuatoriana de Estudios Históricos Americanos, 1(1), 33-63.

Kristal, Efraín. (1991). Una visión urbana de los andes. Génesis y desarrollo del indigenismo en el Perú 18481930. Lima: Instituto de Apoyo Agrario.

Larrea, Carlos. (1965) [1922]. Introducción al Estudio Histórico sobre los Cañaris, Cuenca: Imprenta de la Universidad de Cuenca.

Larrea, Carlos. (1988). Tres historiadores. Velasco, González Suárez, Jijón y Caamaño. Quito: Casa de la Cultura Ecuatoriana Benjamín Carrión. 
MÉndez, Cecilia. (1995). Incas sí, indios no: Apuntes para el estudio del nacionalismo criollo en el Perú. Lima: Instituto de Estudios Peruanos.

Miño Grijalva, Manuel. (1982). Los cañaris del Perú. Revista del Banco Central del Ecuador5(14), 79-131.

MurúA, Fray Martín de. (1987) [1616]. Historia General del Perú. Madrid: Ed. Manuel Ballesteros.

Oberem, Udo y Hartmann, Roswith. (1979). Apuntes sobre Cañaris en el Cusco y en otras regiones del altiplano peruano boliviano durante la Colonia (pp. 106-123). En Memorias del ler. Congreso Ecuatoriano de Arqueología. Quito: Casa de la Cultura Ecuatoriana.

Pease García Yrigoyen, Franklin. (1963). Los últimos incas del Cuzco. Boletín del Instituto Riva-Agüero, (6), 150-192.

Robin-Azevedo, Valérie Carmen y Salazar-Soler, Carmen. (Eds.). (2009). El regreso de lo indígena. Retos, problemas y perspectivas. Lima: Instituto Francés de Estudios Andinos, Centro Bartolomé de las Casas.

SAntos, Roberto. (1986). Los mitimaes cañaris-chachapoyas de Copacabana (siglos XVI- XVII). La Paz: Centro de Investigaciones Históricas.

Solari Pita, Mirko. (2015). Les chemins de l'ethnicité: parcours identitaires des descendants des mitmas cañaris dans la région andine (XVIe-XXIe siècle) (tesis doctoral). École des hautes études en sciences sociales, París.

Velasco, Juan de. (1960) [1844]. Biblioteca Ecuatoriana Mínima. La Colonia y la República. Padre Juan de Velasco. Quito: Undécima Conferencia Interamericana.

Presentado: 19/08/2019

Aceptado: 08/03/2021

Publicado online: 10/08/2021 